\title{
Comparison between an upper airway obstruction score and airway endoscopy to detect airway injury associated with endotracheal intubation in children
}

\author{
Andréa M.G. Cordeiro, ${ }^{1}$ Daniela C. Souza, ${ }^{2}$ Regina H. Quinzani, ${ }^{3}$ Eduardo J. Troster ${ }^{4}$
}

\begin{abstract}
Objective: To compare an upper airway obstruction score vs. airway endoscopy to detect moderate or severe airway injury associated with endotracheal intubation in children.

Methods: Prospective study. Airway endoscopy and clinical evaluation were performed after extubation. Airway injuries identified on endoscopy or according to the upper airway obstruction score were classified as minor, moderate or severe. The obstruction score was assessed in terms of sensitivity, specificity, positive and negative predictive values and likelihood ratio to detect moderate or severe injuries.

Results: Among 215 patient, endoscopy was normal in 10.2\%. Minor lesions were diagnosed in 54.9\% of the patients, followed by moderate (24.2\%) and severe (10.7\%) lesions. In 163 patients with upper airway obstruction, the score classified injuries as minor in $23.3 \%$, moderate in $41.4 \%$ and severe in $11.2 \%$. A score $\geq 4$ had a sensitivity of $73.3 \%$ (95\% CI: 67.4-79.2) to detect moderate or severe injuries and a specificity of $58.6 \%$ (95\% CI: 52.0-65.2) to exclude patients without moderate or severe lesions. The positive predictive value of a score $\geq 4$ was $48.7 \%$ (95\% CI: $42.0-55.4$ ). In patients with a score $\leq 3$ the chance of not presenting moderate or severe injuries was $80.4 \%$ (95\% CI: 75.1-85.7). The probability of a patient with moderate or severe injuries to present a score $\geq 4$ was $73.3 \%$ compared to patients without those injuries (41.4\%) (1.8 fold higher).

Conclusions: The score reliably ruled out moderate or severe airway injury in patients with minor upper airway distress. On the other hand, scores $\geq 4$ presented a low specificity. Clinical evaluation can be useful to rule out patients with minor airway injuries.
\end{abstract}

J Pediatr (Rio J). 2003;79(6):543-9: Intratracheal intubation, child, newborn, airway obstruction, airway injury, subglottic stenosis.

1. MSc. Assistant physician, Pediatric Intensive Care Unit, Hospital Universitário, Universidade de São Paulo (USP), São Paulo, SP, Brazil.

2. Assistant physician, Pediatric Intensive Care Unit, Hospital Universitário, Universidade de São Paulo (USP), São Paulo, SP, Brazil.

3. Physical therapist, Pediatric Intensive Care Unit, Hospital Universitário, Universidade de São Paulo (USP), São Paulo, SP, Brazil.

4. PhD. Chief physician, Pediatric Intensive Care Unit, Instituto da Criança, School of Medicine, Universidade de São Paulo (USP), São Paulo, SP, Brazil.

Manuscript received May 08 2003, accepted for publication Sep 032003.

\section{Introduction}

Upper airway obstruction resulting from tracheal intubation presented incidences that varied between 2.4 and $68.7 \%$ in pediatric studies published in international literature ${ }^{1-5}$ and in our country. ${ }^{6,7}$ Clinical evaluation of post-intubation upper airway obstruction was performed in a dichotomous manner; the presence or absence of stridor in some studies ${ }^{1,5,8}$ or by means of analysis of other variables indicative of respiratory distress. ${ }^{2,4,9,10}$ 
Refinement of the clinical evaluation equates to an attempt to gauge the severity of upper airway respiratory distress by means of the application of scores. ${ }^{3,11-14}$ Studies which quantified the degree of upper airway respiratory distress with scores showed that between $68.7^{7}$ and $78.0 \%$ of the patients presented positive scores. ${ }^{15}$ The results of these studies are difficult to compare since the scores were based on the evaluation of different parameters and different values were allocated to each variable and consequentially to the maximum value. Stridor was the only variable used in all the scores, although it was graduated in different ways. Downes \& Rapahelly ${ }^{11}$ proposed a score for assessing upper airway respiratory distress resulting from viral croup, in which stridor was graded as: absent, inspiratory or inspiratory and expiratory. In the 17 point score proposed by Kemper et al., ${ }^{15}$ validated with 25 child trauma victims, stridor was graded as absent, present-dormant or severe. The same stridor grades were adopted by Nutman et al. ${ }^{12}$ for an analysis of 28 children. A score for croup, used in a study by Anene et al. ${ }^{5}$ involving 66 children, defined stridor in a similar manner to Downes and Raphaelly..$^{11}$ Harel et al., ${ }^{13}$ however, graded stridor at four levels: absent, audible with a stethoscope, easily audible with reasonable inspiratory airflow and easily audible with reduced inspiratory airflow. In this proposal the assessment of stridor was associated with inspiratory airflow that was dealt with separately $5,12,15$ or not included ${ }^{3,11}$ in the other score. More objective variables, such as oxygen saturation, ${ }^{15}$ respiratory frequency ${ }^{13,15}$ and heart rate ${ }^{13}$ were also graded differently.

Clinical evaluation of upper airway respiratory distress secondary to upper airway lesions in patients who have undergone tracheal intubation is a diagnosis instrument of extreme value, primarily due to the fact that its availability is unrestricted. Nevertheless, its efficacy needs to be compared with another diagnostic method in order to define its utility and limitations. The objective of the present study is to analyze the performance of an upper airway obstruction score for the detection of children with airway lesions associated with tracheal intubation, classified as moderate and severe.

\section{Methods}

During the period between October 1999 and October 2001 all patients admitted to the Pediatric \& Neonatal Intensive Care Unit at the University Hospital of the Universidade de São Paulo who required endotracheal intubation were included in the study. Newborns whose weight was less than $1,250 \mathrm{~g}$ and patients that died before extubation were excluded.

The following characteristics of the study population were described and analyzed: age (up to 28 days old or more than 28 days old), gender, weight, pediatric risk of mortality (PRISM - for those more than 28 days old), ${ }^{16}$ primary diagnoses at admission, indications for intubation by organ failure or insufficiency and duration of intubation.
After extubation, the patients underwent an endoscopic examination of the airway, which was performed by the same physician for all patients. A nonrandom sample of 50 examinations was recorded on video and interpreted by a second observer blinded to the results established by the first, in order to check agreement between the diagnoses established. Endoscopy findings were classified according to the proposal made by Benjamin ${ }^{17}$ who defined endoscopic aspects, topography and the prognosis associated with supraglottic, glottic and subglottic lesions (Table 1).

Based on this classification we adopted the following terminology:

Lesions with a potential for favorable outcome were defined as minor and included edema (with the exception of those types of edema listed below), hyperemia and erosion.

Lesions which would probably develop sequelae were defined as moderate and included subglottic edema, edema the vocal folds, ulceration, tongues of granulation tissue, laceration, hematoma, dislocated arytenoid cartilage, exposed cartilage and ulcerating depressions.

Intubation sequelae were defined as severe lesions and included stenosis, synechia, paresis or paralysis of the vocal folds, granuloma, fibrous nodules, scar tissue furrows and cricoarytenoid junction fixation.

Clinical assessment during the post-extubation period consisted of the application of the upper airway obstruction score proposed by Downes \& Raphaelly ${ }^{11}$ with a maximum score of 10 (Table 2). The score was applied by two observers (second-year pediatric resident or third-year pediatric intensive care resident and the attending physician) 30 minutes after completion of the endoscopic examination. Sequential clinical assessment was performed during the first 24 hours after extubation for monitoring purposes. The scores used for analysis were those recorded after the endoscopic examination. If there was disagreement between the observers in terms of the values attributed to each variable and the total score, the opinion of the most experienced observer was accepted. Those responsible for the clinical assessment had access to the endoscopy results so it is not possible to be sure that all patients were assessed in a blind fashion. Upper airway respiratory distress was graded as absent when the score was zero, mild for scores between 1 and 3; moderate for scores between 4 and severe for scores equal to or greater than 7 .

Patients requiring reintubation participated again in the study and were reassessed clinically and endoscopically after each extubation. When defining endoscopy findings, only new lesions were considered as compared to previous exams. In analyzing upper airway respiratory distress the highest values were taken into account.

Informed consent was obtained for all patients from their parents or legal guardians. The study was approved by the Research Ethics Committee at the USP University Hospital. 
Table 1 - Endoscopy findings after extubation and prognosis

\begin{tabular}{|c|c|c|}
\hline Type & Endoscopic aspect & Possible evolution \\
\hline Early and nonspecific & $\begin{array}{l}\text { Hyperemia } \\
\text { Edema } \\
\text { Erosion }\end{array}$ & Remission \\
\hline Edema & $\begin{array}{l}\text { Protrusion of ventricular mucosa } \\
\text { Vocal fold edema } \\
\text { Subglottic edema }\end{array}$ & $\begin{array}{l}\text { Remission } \\
\text { Reinke's edema } \\
\text { Subglottic obstruction }\end{array}$ \\
\hline Granulation tissue & $\begin{array}{l}\text { "Tongues" from the vocal process } \\
\text { of the arytenoid cartilages }\end{array}$ & $\begin{array}{l}\text { Remission } \\
\text { Granuloma } \\
\text { Fibrous nodules } \\
\text { Interarytenoid synechia }\end{array}$ \\
\hline Ulceration & $\begin{array}{l}\text { Ulcerating depressions } \\
\text { Annular ulceration in posterior glottis } \\
\text { Subglottic ulceration } \\
\text { with cricoid involvement }\end{array}$ & $\begin{array}{l}\text { Scar tissue furrows } \\
\text { Synechia of the posterior glottis } \\
\text { Subglottic stenosis }\end{array}$ \\
\hline Miscellaneous & $\begin{array}{l}\text { Laceration } \\
\text { Bleeding } \\
\text { Dislocated arytenoid cartilage } \\
\text { Perfurations } \\
\text { Cricoid ulceration }\end{array}$ & $\begin{array}{l}\text { Scar } \\
\text { Hematoma } \\
\text { Cricoarytenoid junction fixation } \\
\text { Infection or abcess } \\
\text { Fistula }\end{array}$ \\
\hline
\end{tabular}

Characteristics of the lesions and the population were described by medians and 25-75 interquartile variation to measure dispersal. The results from a sample of the endoscopic examinations were evaluated for interobserver agreement using the Kappa test. The clinical

Table 2 - Parameters assessed by means of upper airway obstruction score ${ }^{12}$

\begin{tabular}{|c|c|c|c|}
\hline \multirow[t]{2}{*}{ Parameter } & \multicolumn{3}{|c|}{ Value } \\
\hline & $\mathbf{0}$ & 1 & 2 \\
\hline Inspiratory sounds & Normal & Snoring & Slow \\
\hline Wheezing & Absent & Inspiratory & $\begin{array}{l}\text { Inspiratory } \\
\text { and } \\
\text { expiratory }\end{array}$ \\
\hline Cough & Absent & Hoarse crying & Barking \\
\hline $\begin{array}{l}\text { Retraction } \\
\text { and MNA* }\end{array}$ & Absent & $\begin{array}{l}\text { MNA* and } \\
\text { suprasternal } \\
\text { retraction }\end{array}$ & $\begin{array}{l}\text { MNA*, } \\
\text { subcostal, } \\
\text { intercostal and } \\
\text { suprasternal } \\
\text { retraction }\end{array}$ \\
\hline Cyanosis & Absent & Room air & $\mathrm{FiO}_{2}>40 \% \S$ \\
\hline
\end{tabular}

* MNA: movement of the nasal ala; ${ }^{\S} \mathrm{FiO}_{2}$ : fraction of inhaled oxygen. score's performance in terms of detecting children with moderate or severe lesions, in comparison with the endoscopy findings, was evaluated by sensitivity and specificity calculations, positive and negative predictive values and the likelihood ratio.

\section{Results}

One thousand and fourteen patients were admitted to the PICU and 421 to the NICU. The total population of the Unit during this period was 1,435 . Of these, 313 $(21.8 \%)$ patients were subjected to tracheal intubation. Fifty-eight patients were excluded (35 died, informed consent was denied for 12 and 11 presented weight below $1,250 \mathrm{~g}$ ). In 40 cases it was not possible to perform the examination (eight because informed consent could not be obtained, 14 because of operational difficulties, 10 because of accidental extubation and eight patients were transferred while intubated).

Table 3 contains the main characteristics of the 215 patients studied. The majority was composed of infants and children $(71.6 \%)$. Within this group there was a predominance of infants $(60.5 \%)$. Male patients predominated in both groups, $57.4 \%$ of those less than 28 days old and $55.2 \%$ of those older than 28 days. The 
PRISM $^{16}$ score shows that the population older than 28 days, to which it applies, presented a low risk of death on admission.

Primary diagnoses on admission were classified, according to systems affected, as respiratory, cardiovascular, neurological and others. Respiratory diseases were the most prevalent among both older children $(56.5 \%)$ and neonates $(54.3 \%)(\mathrm{p}=0.67)$. Bronchopneumonia/pneumonia were the most common respiratory diagnoses among the 154 older patients (53.9\%). Among the newborns, however, they accounted for just $22.9 \%$ of the admission diagnoses ( $\mathrm{p}$ $<0.001)$. Hyaline membrane disease was the most prevalent respiratory disease, diagnosed in $37.7 \%$ of the newborns.

Intubation was indicated for respiratory insufficiency in the majority of cases (57.8\% of the patients over 28 days old and $73.8 \%$ of the newborns). Neurological instability was a rare indication for intubation in this population, occurring in five of the older patients (3.3\%) and two neonates (3.3\%). Comparing the two age groups in terms of indication for intubation, we found statistically significant differences only for respiratory insufficiency, which prevailed among the newborns $(\mathrm{p}=0.04)$.

\section{Endoscopic study}

A normal endoscopic examination was observed in just $10.2 \%(22 / 215)$ of the patients of whom six were newborns and 16 were children older than 28 days $(\mathrm{p}=0.89)$. For the remaining $89.8 \%$ of the population studied (95\% CI: 85.893.8), being 55 neonates and 138 children older than 28 days, at least one airway lesion was detected and a total of 507 lesions were noticed. As there was often a constellation of lesions in a single patient we presented the percentage of patients with lesions of a specific severity. In so doing we took into account the presence of at least one severe lesion, at least one moderate lesion or only minor lesions. We observed that $54.9 \%$ of the patients (95\% CI: $48.3-61.5$ ) exhibited only minor lesions. Patients with at least one moderate lesion accounted for $24.2 \%$ of the population studied (95\% CI: 18.5-30.0), while those with severe lesions made up $10.7 \%$ (95\% CI: 6.6-14.8).

The greatest incidence among the moderate lesions was of vocal folds edema in both groups (13.4\% of the lesions for children over 28 days and $12.8 \%$ of the lesions for newborns $)(p=0.96)$. Severe lesions occurred mainly at the level of the glottis. Seventy-three point $7 \%$ of severe injuries were at this anatomical location in the post-neonatal group and $60 \%$ in the newborn group $(\mathrm{p}=0.67)$. Synechia and fibrous nodules on the vocal folds had the highest incidence among severe lesions in children over 28 days old (each representing $1.7 \%$ of the total number of lesions). Among the neonates, synechia, stenosis and fibrous nodules on the vocal folds presented similar incidence $(2.0 \%$ of the total number of lesions for each of them). Subglottic stenosis had an incidence of $2.8 \%$ of the population studied (6/215 three newborns and three post-neonatal patients).

Fifty examinations were recorded on video. The sample analyzed consisted of five normal exams and 45 exams with abnormalities. The prognosis of the lesions in question presented a profile similar to that of the total group of lesions. Minor lesions occurred in $62.0 \%$ of the sample, moderate in $23.1 \%$, severe $7.6 \%$ of the sample and other lesions not related to intubation made up 7.3\%. Lesions unrelated to intubation refers to asymptomatic anatomic abnormalities such as type 1 laryngeal cleft in one patient and shortening of the aryepiglottic ligament in two. The rate of agreement between the two observers for the group of fifty exams, according to the Kappa test, was 0.48 (95\% CI: 0.25-0.72).

\section{Clinical assessment}

Based on the immediately post-extubation score, the 215 patients were divided into four groups according to

Table 3 - Main characteristics of the 215 patients studied

\begin{tabular}{|c|c|c|}
\hline \multirow[t]{2}{*}{ Variable } & \multicolumn{2}{|c|}{ Median (interquartile range $25 \%$ to $75 \%$ ) } \\
\hline & $>28 \mathrm{~d}(\mathrm{n}=154)$ & $\leq 28 \mathrm{~d}(\mathrm{n}=61)$ \\
\hline Age & 4 months ( 2 to 11$)$ & 5.4 days (3.0 to 9.6 ) \\
\hline Weight ${ }^{\S}$ & $6.2(4.3$ to 9.0$)$ & $2,700(1,826$ to 2,707$)$ \\
\hline PRISM* & $12(11$ to 16$)$ & - \\
\hline Risk of mortality $(\%)^{*}$ & $9.0(4.8$ to 14.4$)$ & - \\
\hline Intubation time $\#$ & 5.0 (3 to 10 days $)$ & 4.4 (2.6 to 8.0 days) \\
\hline
\end{tabular}


severity of respiratory discomfort. In Table 4 the relationships between upper airway respiratory distress scores and endoscopic lesions are described. As each patient frequently presented more than one lesion, the lesion with the worst prognosis was used to define lesion group.

Absence of upper airway respiratory distress $($ score $=0)$ was observed in $24.2 \%$ of the population. The remaining 163 patients $(75.8 \%$; $95 \%$ CI: 70.1-81,5) had some degree of upper airway distress noted. The majority of the patients (41.4\%) had developed moderate upper airway distress (score between 4 and 6) (Table 4).

Taking just the patients with moderate or severe lesions, we noted that the sensitivity of a score equal to or greater than 4 (moderate or severe distress) for detecting the presence of at least one lesion of this nature was $73.3 \%$ (95\% CI: 67.4-79.2). The score was capable of ruling out patients without moderate or severe lesions in $58.6 \%$ of cases (95\% CI: 52.0-65.2) (Table 5). Patients with scores greater than or equal to 4 had a probability of presenting a moderate or severe lesion (the score's positive predictive value) of $48.7 \%$ (95\% CI: 42.0-554). Patients scoring 3 or less had a probability of not presenting a moderate or severe lesion (the score's negative predictive value) was $80.4 \%$ (95\% CI: 75.1-85.7) (Table 5). The probability of a patient with a moderate or severe lesion presenting a moderate or severe upper airway obstruction score was $73.3 \%$ while the probability of patients without moderate or severe lesions doing so was $41.4 \%$ (Table 5).

\section{Discussion}

In the present study we attempted to compare the efficiency of an upper airway obstruction score in detecting patients with airway lesions related to endotracheal intubation diagnosed by respiratory endoscopy. We observed a high incidence of airway lesions of various degrees of severity. The rate of agreement between two observers for a series of 50 exams, by the Kappa test, indicates moderate agreement, meaning that the results found should be close to reality with minimal observer bias. Nevertheless, certain comments should be made. It is not possible to exclude systematic observer bias, based on differentiated assessments of patient subgroups, since the researcher responsible for airway endoscopy was a member of the ICU staff. This being the case, she had knowledge of the patient's progress and may have applied herself to the examinations of certain patients (those of greater or lesser risk) differently than to the examinations of others. This would have been avoided if the observer had remained independent of the treating team, which was not possible. We attempted to minimize the problem by comparing the analysis provided with a second viewer. Despite both observers being familiar with the classification adopted, the fact that we did not test agreement for the different lesion severity groups individually, makes it impossible for us to claim that the moderate agreement is valid for all types of lesion.

The post-extubation clinical assessment was based on a score proposed for assessment of viral croup. The application of scores for viral croup to post-extubation upper airway respiratory distress is based on the pathophysiological similarities between the two conditions, such as inflammatory process with edema of mucosa and submucosa. It is worth pointing out that airway damage due to intubation may involve other types of lesion associated or not with edema, such as erosion, ulceration and granulation tissue among others. ${ }^{17}$ The clinical score evaluates the degree of airway obstruction as a consequence of an airway injury, which may be different for the two different situations since the lesions are not necessarily identical. The ideal score should have a high level of performance as measured by its sensitivity, specificity and positive and negative predictive values; be easily applied by medical personnel and also present minimum interobserver variation.

Studies applying clinical scores in order to compare therapeutic strategies for the relief of post-extubation upper airway respiratory distress ${ }^{3,7,11-15}$ have not assessed the accuracy of the scores for detecting lesions in the airway when compared with other diagnostic tools.

Table 4 - Upper airway respiratory distress scores and endoscopic lesions in 215 patients

\begin{tabular}{lccccc}
\hline Distress score & Severe & \multicolumn{2}{c}{ Endoscopic lesions } & & Total (\%) \\
& Moderate & Mild & Absent & \\
\hline Severe & 5 & 17 & 2 & 0 & $24(11.2)$ \\
Moderate & 8 & 25 & 56 & 0 & $89(41.4)$ \\
Mild & 10 & 6 & 30 & 4 & $50(23.3)$ \\
Absent & 0 & 4 & 30 & 18 & $52(24.2)$ \\
Total (\%) & $23(10.7)$ & $52(24.2)$ & $118(54.9)$ & $22(10.2)$ & $215(100.0)$ \\
& & & & &
\end{tabular}


Table 5 - Score performance $\geq 4$ according to the endoscopic examination

\begin{tabular}{lcccc}
\hline & & \multicolumn{2}{c}{$\begin{array}{c}\text { Moderate ou severe lesion } \\
\text { Present }\end{array}$} & Total \\
& Absent & \\
\hline Moderate or severe score & Present & 55 & 58 & 113 \\
& Absent & 20 & 82 & 102 \\
Total & & 75 & 140 & 215 \\
\hline
\end{tabular}

Sensitivity $=73.3 \%(95 \% \mathrm{Cl}: 67.4-79.2)$;

Specificity $=58.6 \%(95 \% \mathrm{Cl}: 52.0-65.2)$;

Positive preditive value $=48.7 \%(95 \% \mathrm{Cl}: 42.0-55.4)$;

Negative preditive value $=80.4 \%(95 \% \mathrm{Cl}: 75.1-85.7)$

Probability ratio $=1.8$.

Fan et al. ${ }^{18}$ attempted to establish such a comparison with the endoscopic examination using a qualitative clinical assessment based on the absence of symptoms, the presence of hoarseness and the presence of stridor. They observed, among 73 neonates, that stridor was present in 12 patients with moderates or severe lesions and absent in 20 who had such lesions. The authors concluded that for the detection of moderates or severe lesions, stridor offered a high specificity (100\%) (95\% CI: 96,5-100), but low sensitivity (38\%) (95\% CI: 23.152.8). The predictive value of stridor for detecting the presence of moderates or severe laryngeal lesions was $100 \%$. A study evaluating risk factors for subglottic stenosis in newborns observed that among 102 patients the presence of stridor offered a sensitivity of $80 \%(95 \%$ CI: $55.2-100.0)$ and specificity of $91 \%$ (95\% CI: $85.1-$ 96.8 ) as a predictive factor of moderate to severe subglottic stenosis. ${ }^{19}$ Judging by the confidence intervals for sensitivity and specificity, it can be said that data on the performance of stridor compared with endoscopy is insufficient.

In the present study we observed that the application of a score which includes other variables in addition to stridor presented a high sensitivity but a low specificity. It is highly likely that the clinical parameters included in this score are not capable of differentiating distress resulting from upper airway obstruction from that secondary to lower respiratory and/or pulmonary parenchyma disease. The greatest advantage of this score was to allow the exclusion of those patients who - by presenting scores of 3 or less - had an $80 \%$ probability of not having moderate or severe lesions. Nevertheless, we must take into consideration the fact that we did not attempt to calculate interobserver agreement for the clinical score, which may have resulted in an observer bias. Kemper et al. ${ }^{15}$ demonstrated a variation between three observers in the application of clinical parameters for the analysis of post-intubation upper airway respiratory distress. They observed lower agreement for variables that may suffer from individual interpretation, such as degree of stridor (83\% agreement) $(95 \%$ CI: 68.8-97.2) and air entry ( $85 \%$ agreement) (95\% CI: 71.5 98.5). Greater agreement was demonstrated for more objective variables such as oxygen saturation (95\% agreement) (95\% CI: 86.7-100) and respiratory rate (89\% agreement) (95\% CI: 77.2-100). Even for objective variables, the confidence intervals show that agreement may be as low as $77.2 \%$ for respiratory rate and $86.7 \%$ for oxygen saturation. These results probably reflect different methods of recording respiratory rate and frequent oscillations in oximetry during the observation period.

The limitations of clinical assessment are recognized by many authors, ${ }^{15,18,20}$ but these do not invalidate its utility for tracking patients nor nullify its unrestricted availability. In the present study we observed that the score's performance was adequate in suggesting the absence of severe or moderate airway injuries for those with mild discomfort. For those with moderate or severe discomfort the score offered a low sensitivity and specificity. Clinical assessment can be a useful tracking method. Future studies are required to identify clinical variables with greater specificity for upper airway involvement.

\section{References}

1. Rivera R, Tibballs J. Complications of endotracheal intubation and mechanical ventilation in infants and children. Crit Care Med. 1992;20:193-9

2. Couser RJ, Ferrara TB, Falde B, Johnson K, Schilling CG, Hoekstra RE. Effectiveness of dexamethasone in preventing extubation failure in preterm infants at increased risk for airway edema. J Pediatr. 1992;121:591-6 
3. Deakers TW, Reynolds G, Stretton M, Newth CJ. Cuffed endotracheal tubes in pediatric intensive care. J Pediatr. 1994;125:57-62.

4. Shin OK, Sou OB, Yong WH, Hye WC, Bum KC. Incidence and predictors of postextubation laryngeal edema in pediatric patients with congenital heart disease. Yonsei Med J. 1995;36:53-7.

5. Anene O, Meert KL, Uy H, Simpson P, Sarnaik AP. Dexamethasone for prevention of postextubation airway obstruction: a prospective, randomized, double blind, placebocontrolled trial. Crit Care Med. 1996;24:1666-9.

6. Fernandes ICO, Fernandes JC, Cordeiro A, Hsin SH, Bousso A, Ejzenberg B, et al. Eficácia e segurança do uso da adrenalina-L na laringite pós-entubação utilizada em associação com a dexametasona. J Pediatr (Rio J). 2001;77:179-88

7. Cesar RG. Dexametasona e L-epinefrina na profilaxia da laringite e do desconforto respiratório pós-extubação em pediatria [dissertation]. São Paulo, SP: Faculdade de Ciências Médicas da Santa Casa de São Paulo; 2000.

8. Fan LL, Flynn JW, Pathak DR, Madden WA. Predictive value of stridor in detecting laryngeal injury in extubated neonates. Crit Care Med. 1982;10:453-5.

9. Kemper KJ, Benson MS, Bishop MJ. Predictors of postextubation stridor in pediatric trauma patients. Crit Care Med. 1991;19:352-5.

10. Tellez DW, Galvis AG, Storgion SA, Amer HN, Hoseyni M, Deakers TW. Dexamethasone in the prevention of postextubation stridor in children. J Pediatr. 1991;118:289-94.

11. Downes JJ, Raphaely RC. Pediatric intensive care. Anesthesiology. 1975;43:238-50.

12. Nutman J, Brooks LJ, Deakins KM, Baldesare KK, Witte MK, Reed MD. Racemic versus 1-epinephrine aerosol in the treatment of postextubation laryngeal edema: results from a prospective, randomized, double-blind study. Crit Care Med. 1994;22:1591-4.

13. Harel Y, Vardi A, Quigley R, Brink LW, Manning SC, Carmody TJ, et al. Extubation failure due to post-extubation stridor is better correlated with neurologic impairment than with upper airway lesions in critically ill pediatric patients. Int J Pediatr Otorhinolaryngol. 1997;39:147-58.
14. Kemper KJ, Benson MS, Bishop MJ. Predictors of postextubation stridor in pediatric trauma patients. Crit Care Med. 1991;19:352-5.

15. Kemper KJ, Benson MS, Bishop MJ. Interobserver variability in assessing pediatric postextubation stridor. Clin Pediatr (Phila). 1992;31:405-8

16. Pollack MM, Ruttimann UE, Getson PR. Pediatric Risk of Mortality (PRISM) Score. Crit Care Med. 1988;16:1110-6.

17. Benjamin B. Laryngeal trauma from intubation: endoscopic evaluation and classification. In: Cummings CW, Fredrickson JM, Harker LA, Krause CJ, Schuller DE, editors. Otolaryngology Head and Neck Surgery. 2nd ed. Mosby-Year Book; 1993. p.1875-96.

18. Fan LL, Flynn JW, Pathak DR, Madden WA. Predictive value of stridor in detecting laryngeal injury in extubated neonates. Crit Care Med. 1982;10:453-5.

19. Sherman JM, Lowitt S, Stephenson C, Ironson G. Factors influencing acquired subglottic stenosis in infants. J Pediatr. 1986;109:322-7.

20. Waisman Y, Klein BL, Boenning DA, Young GM, Chamberlain JM, O'Donnell R, et al Prospective randomized double-blind study comparing L-epinephrine and racemic epinephrine aerosols in the treatment of laryngotracheitis (croup). Pediatrics. 1992;89:302-6

Corresponding author:

Andréa Maria G. Cordeiro

Rua Jacques Felix, 96/94

CEP 04509-000 - São Paulo, SP, Brazil

Tel.: +55 (11) 3044.7179/3842.2472

Fax: +55 (11) 3022.3006

E-mail: amgcordeiro@uol.com.br/venturag@uol.com.br 